\title{
Hemodynamic Assessment of Pregnant People with and without Obesity by Noninvasive Bioreactance: A Pilot Study
}

\author{
Ernesto A. Figueiro-Filho, MD, $\mathrm{PhD}^{1,5}$ Na T. S. Robinson, $\mathrm{MD}^{1,2}$ Jose Carvalho, MD, $\mathrm{PhD}^{3}$ \\ Johannes Keunen, $\mathrm{MD}^{1}$ Monique Robinson, MD ${ }^{4}$ Cynthia Maxwell, MD ${ }^{1}$
}

\footnotetext{
${ }^{1}$ Department of Obstetrics and Gynecology, Division of Maternal Fetal Medicine, Mount Sinai Hospital, Toronto, Ontario, Canada

2 Department of Obstetrics and Gynecology, Queen Elizabeth Hospital, Barbados

${ }^{3}$ Department of Anaesthesia, Mount Sinai Hospital, Toronto, Ontario, Canada

${ }^{4}$ Department of Cardiovascular Medicine, Cleveland Clinic

Foundation, Cleveland, Ohio

${ }^{5}$ Maternal Fetal Medicine Division, Department of Obstetrics and Gynecology,

University of Saskatchewan, Saskatoon, Saskatchewan, Canada
}

\begin{abstract}
Address for correspondence Ernesto A. Figueiro-Filho, MD, PhD, Maternal Fetal Medicine Division, Department of Obstetrics and Gynecology, University of Saskatchewan, Saskatoon, SK-S7N 5A2, Canada (e-mail: ernesto.figueiro@saskhealthauthority.ca).
\end{abstract}

AJP Rep 2022;12:e69-e75.

\begin{abstract}
Keywords

- pregnancy

- noninvasive cardiac output monitoring

- obesity

- hemodynamic

- pilot study

Objective This study aimed to identify cardiovascular differences between pregnant people with and without obesity for trimester-specific changes in hemodynamic parameters using noninvasive cardiac output monitoring (NICOM).

Study Design This study is a pilot prospective comparative cohort between pregnant people with and without obesity. Hemodynamic assessment was performed with NICOM (12-14, 21-23, and 34-36 weeks) during pregnancy.

Results In first trimester, pregnant people with obesity had higher blood pressure, stroke volume (SV), total peripheral resistance index (TPRI), and cardiac output (CO). Pregnant people with obesity continued to have higher SV and cardiac index (second and third trimesters). During the first trimester, body mass index (BMI) positively correlated with SV, TPRI, and CO. Fat mass showed a strong correlation with TPRI. BMI positively correlated with $\mathrm{CO}$ during the second trimester and fat mass was positively associated with $\mathrm{CO}$. During the third trimester, TPR negatively correlated with BMI and fat mass.

Conclusion Fat mass gain in the period between the first and second trimesters in addition to the hemodynamic changes due to obesity and pregnancy contribute to some degree of left ventricular diastolic dysfunction which was manifested by lower SVs. Future work should investigate the possible causative role of obesity in the cardiovascular changes identified in people with obesity.
\end{abstract}

The obesity pandemic continues unabated, and according to the latest assessments, 300 million female people worldwide have obesity. ${ }^{1}$ In the general population, obesity is defined as a body mass index (BMI) greater than $30 \mathrm{~kg} / \mathrm{m}^{2}$. Obesity can alter hemodynamic function by causing higher cardiac output $(\mathrm{CO})^{2,3}$ and higher stroke volume (SV). ${ }^{4,5}$ Obesity is also received

June 10,2020

accepted

October 8, 2021
DOI https://doi.org/

$10.1055 / \mathrm{s}-0041-1742270$. ISSN 2157-6998.

\footnotetext{
(C) 2022. The Author(s).

This is an open access article published by Thieme under the terms of the Creative Commons Attribution-NonDerivative-NonCommercial-License, permitting copying and reproduction so long as the original work is given appropriate credit. Contents may not be used for commercial purposes, or adapted, remixed, transformed or built upon. (https://creativecommons.org/ licenses/by-nc-nd/4.0/) Thieme Medical Publishers, Inc., 333 Seventh Avenue, 18th Floor, New York, NY 10001, USA
} 
associated with altered myocardial geometry ${ }^{6}$ and heart failure. $^{7,8}$

Obesity in pregnancy is defined as a BMI greater than or equal to $30 \mathrm{~kg} / \mathrm{m}^{2}$ at the first antenatal consultation and confers a high-risk status on the pregnancy. ${ }^{9}$ In the United States, alone half of all pregnant people have overweight or obesity. ${ }^{10}$ Pregnant people with obesity are at increased risk for gestational hypertension, ${ }^{11}$ preeclampsia, ${ }^{12}$ gestational diabetes, ${ }^{11,13}$ maternal mortality, ${ }^{14}$ and are more likely to have caesarean births. ${ }^{15,16}$ There are also serious implications for the fetus including risk of stillbirth, ${ }^{17}$ macrosomia, ${ }^{18}$ and congenital abnormalities. ${ }^{19}$ Infants born to people with obesity more often demonstrate fetal distress in labor, meconium aspiration, and low Apgar's scores, ${ }^{20}$ and, in future, life as adults with an increased risk of premature death. $^{21}$

Identifying cardiovascular differences between pregnant people with and without obesity might assist in identifying targets for intervention to improve outcomes in these cohorts of patients.

Traditionally, the gold standard for central hemodynamic monitoring has been invasive through the use of a pulmonary artery catheter (PAC). Placement of these lines and the interpretation of the readings require considerable specialist expertise. ${ }^{14}$ The development of transthoracic bioreactance monitoring has been revolutionary, as it permits noninvasive, bedside monitoring of the SV, and CO. Transthoracic bioreactance methods have been validated against open heart porcine models, ${ }^{22}$ pulse contour analysis, ${ }^{23}$ and the PAC. ${ }^{22,24}$ Transthoracic bioreactance monitoring has been safely used in pregnancy ${ }^{25-28}$ where it has demonstrated hemodynamic differences between preeclamptic and normotensive pregnant people. ${ }^{25,28}$

We hypothesized that by using noninvasive cardiac output monitoring (NICOM), we would be able to detect hemodynamic differences between pregnant people with and without obesity during the course of pregnancy.

\section{Methods}

\section{Study Population}

This prospective comparative cohort pilot study was conducted at a large tertiary care referral center (Mount Sinai Hospital, Toronto, Canada). We recruited two cohorts of pregnant people with and without obesity. At the time of initial booking into local antenatal clinic, people with obesity were identified by BMI greater than or equal to $30 \mathrm{~kg} / \mathrm{m}^{2}$ and people without obesity by BMI 18 to $25 \mathrm{~kg} / \mathrm{m}^{2}$.

All recruited patients were at least 18 years old and were followed longitudinally throughout their pregnancies. All patients agreed to participation by giving informed consent. The study was approved by the local institutional review board.

\section{Study Procedures}

Patients were interviewed and pertinent past medical and social history were collected. Height was measured at the patient's first visit. Once per trimester (12-14, 21-23, and
34-36 weeks), all enrolled patients underwent the following assessments:

\section{Anthropometric Measurements}

- Weight in kilograms (kg) was measured on a standard scale.

- Body fat was assessed using skin fold measurements at the triceps and thigh level with skinfold calipers.

\section{Cardiovascular Measurements}

- Resting systolic and diastolic blood pressure was measured with a standard sphygmomanometer with an appropriately sized cuff.

- Hemodynamic assessment was performed with the bioreactance-based NICOM system (NICOM, Cheetah Medical Inc.). The NICOM noninvasively measured cardiac function parameters including mean arterial pressure (MAP), CO, cardiac index (CI), SV index (SVI), total peripheral resistance (TPR), and TPR index (TPRI). The definitions, units, and normal values of these parameters are as follows:

- MAP ( $\mathrm{mm} \mathrm{Hg}$ ) defined as the average pressure in a patient's arteries during one cardiac cycle. It is considered a better indicator of perfusion to vital organs than systolic blood pressure (SBP; normal range: $70-105 \mathrm{~mm} \mathrm{Hg}$ ).

- $\mathrm{CO}(\mathrm{L} / \mathrm{min})$ is the amount of blood the heart pumps through the circulatory system in 1 minute (normal range: $4-8 \mathrm{~L} / \mathrm{min}$ ).

- $\mathrm{CI}\left(\mathrm{L} / \mathrm{min} / \mathrm{m}^{2}\right)$ is a hemodynamic parameter that describes the $\mathrm{CO}$ from left ventricle in 1 minute to body surface area, thus relating heart performance to the size of the individual (normal range: $2.5-4 \mathrm{~L} / \mathrm{min} / \mathrm{m}^{2}$ ).

- SVI $\left(\mathrm{mL} / \mathrm{m}^{2} /\right.$ beat $)$ is the amount of blood pumped by left ventricle in one contraction (beat) to body surface area (normal range: $33-47 \mathrm{~mL} / \mathrm{m}^{2}$ /beat).

- TPR (dyne.s $/ \mathrm{cm}^{3}$ ) is the resistance to blood flow offered by all of the systemic vasculature, excluding pulmonary vascular system. TPR is equivalent to systemic vascular resistance (SVR) when the central venous pressure (CVP) is low. NICOM monitor estimates TPR assuming CVP is negligible (e.g., equals to $0)$ and uses same calculation of SVR.

$\mathrm{SVR}=(\mathrm{MAP}-\mathrm{CVP}) \times 80 / \mathrm{CO}$ (normal range: 800 1,200 dyne.s $/ \mathrm{cm}^{3}$ )

- TPRI (dyne.s $/ \mathrm{cm}^{3} / \mathrm{m}^{2}$ ) is the TPR by patient's body surface area (normal range: 1,970-2,390 dyne.s $/ \mathrm{cm}^{3} / \mathrm{m}^{2}$ ).

The patient interfaced with the NICOM system through four disposable surface pregelled and glued double electrodes placed on the patient's skin, providing the connection for measurements of current flowing along the thorax. Two electrodes were placed on upper chest and two were placed on the upper abdomen to act as the source of a constant magnitude and, high-frequency current that provided homogeneous coverage of the thorax with an HF electrical field. 


\section{Data Analysis}

Continuous variables with normal distribution were expressed as means with standard deviations. The significance of comparison was assessed by Student's $t$-test. All $p$ values were two-sided and a value of less than or equal to 0.05 was considered statistically significant. Associations between hemodynamic and anthropometric characteristics were calculated using Pearson's correlation coefficient $(r)$. Statistical analyses were completed using commercially available software (SAS Version 9.2, SAS Institute, Cary, NC).

\section{Results}

Seven pregnant people with obesity and eight with normal weight were enrolled in the study. In the group with obesity, six (6/7) patients completed the study, whereas in the group without obesity, seven (seven of eight) completed the study. One patient with normal weight and one patient with obesity presented with preterm births at 36 and 35 weeks, respectively, before they could be studied during the third trimester. All remaining patients in both groups completed their pregnancies without adverse obstetrical events and all had healthy term infants ( $>37$ weeks). All neonates were discharged with mothers and no admission to neonatal intensive care unit (NICU) was reported. Both groups of women were age-matched at the time of enrolment and were of similar gravidity, parity and gestational age (-Table 1).

Of note, chronic hypertension was identified currently during pregnancy in three of seven (42.8\%) patients with obesity and one of eight (12.5\%) of patients without obesity. In regard to clinical history, people with obesity had higher rates of family history of diabetes (five of seven, $71.4 \%$ vs. five of eight, $62.5 \%$ ), hypertension (six of seven, $85.7 \%$ vs, two of eight, $25 \%$ ), cardiovascular events (five of seven, $71.4 \%$ vs. two of eight, $25 \%$ ), stroke (four of seven, $57.1 \%$ vs. two of eight, $25 \%$ ), and sickle-cell disease (one of seven, $14.2 \%$ vs. 0 ).

People with obesity had significantly higher enrollment BMI ( $39.8 \pm 3.9$ vs. $\left.22 \pm 2.5 \mathrm{~kg} / \mathrm{m}^{2}, p<0.0001\right)$ and fat mass

Table 1 Demographic and anthropometric data of pregnant people with and without obesity at the time of study enrollment

\begin{tabular}{|l|l|l|l|}
\hline & Obese & Nonobese & $p$ \\
\hline$n$ & 7 & 8 & NA \\
\hline Age $(\mathrm{y})$ & $33.7 \pm 5.2$ & $33.1 \pm 2.5$ & 0.79 \\
\hline BMI $\left(\mathrm{kg} / \mathrm{m}^{2}\right)$ & $39.8 \pm 3.9$ & $22.2 \pm 2.5$ & $<0.0001$ \\
\hline Fat mass (\%) & $40.6 \pm 3.6$ & $28.6 \pm 5.9$ & $<0.0001$ \\
\hline Gravity & $3.4 \pm 2.1$ & $1.6 \pm 0.5$ & 0.06 \\
\hline Parity & $1.4 \pm 0.4$ & $1.2 \pm 0.5$ & 0.07 \\
\hline $\begin{array}{l}\text { Gestational age } \\
\text { at enrollment } \\
\text { (weeks) }\end{array}$ & $14.7 \pm 1.7$ & $14.7 \pm 1.9$ & 0.97 \\
\hline
\end{tabular}

Abbreviations: BMI, body mass index; NA, indicates not applicable. Note: Data are expressed as mean \pm standard deviation.
Table 2 Hemodynamic data of pregnant people with and without obesity at the time of study enrollment (first trimester 12-14 weeks)

\begin{tabular}{|l|l|l|l|}
\hline & Obese & Nonobese & $p$ \\
\hline$n$ & 7 & 8 & NA \\
\hline SBP $(\mathrm{mm} \mathrm{Hg})$ & $128 \pm 15$ & $99 \pm 13$ & $<0.01$ \\
\hline $\mathrm{DBP}(\mathrm{mm} \mathrm{Hg})$ & $75 \pm 10$ & $59 \pm 12$ & 0.02 \\
\hline $\mathrm{MAP}(\mathrm{mm} \mathrm{Hg})$ & $92 \pm 13$ & $72 \pm 13$ & 0.01 \\
\hline SV $(\mathrm{mL})$ & $101 \pm 20$ & $75 \pm 13$ & 0.01 \\
\hline $\mathrm{TPR}\left(\mathrm{dyn} / \mathrm{s} / \mathrm{cm}^{5}\right)$ & $1,003 \pm 128$ & $997 \pm 189$ & 0.95 \\
\hline $\mathrm{TPRI}\left(\mathrm{dyn} / \mathrm{s} / \mathrm{cm}^{5} / \mathrm{m}^{2}\right)$ & $2,158 \pm 298$ & $1,665 \pm 394$ & 0.03 \\
\hline $\mathrm{CO}(\mathrm{L} / \mathrm{min})$ & $7.34 \pm 1.15$ & $5.93 \pm 0.73$ & 0.01 \\
\hline $\mathrm{Cl}\left(\mathrm{L} / \mathrm{min} / \mathrm{m}^{2}\right)$ & $3.49 \pm 0.59$ & $3.61 \pm 0.42$ & 0.64 \\
\hline
\end{tabular}

Abbreviations: $\mathrm{Cl}$, cardiac index; $\mathrm{CO}$, cardiac output; DBP, diastolic blood pressure; MAP, mean arterial pressure; NA, indicates not applicable; SBP, systolic blood pressure; SV, stroke volume; TPR, total peripheral resistance; TPRI, total peripheral resistance index. Note: Data are expressed as mean \pm standard deviation.

$(40.6 \pm 3.6$ vs. $28.6 \pm 5.9 \%, p<0.0001)$ when compared with people with normal weight ( - Table 1 ).

In the first trimester assessments, people with obesity had higher SBP, diastolic blood pressure (DBP), MAP, SV, TPRI, and CO (-Table 2).

In the second and third trimesters, people with obesity demonstrated higher SVs and CI, while other parameters remained similar (-Table 3). BMI increased during the latter portions of pregnancy for both groups of people (-Table 3 ). Fat mass increased between the second and third trimesters for people with normal weight, whereas people with obesity demonstrated a reduction. (- Table 3 ).

Anthropometric and hemodynamic data were interrogated for degree of change between trimesters. Between the first and second trimester, blood pressure (SBP and MAP) significantly decreased for people with obesity but remained comparatively higher when compared with people with normal weight. The TPR and TPRI significantly decreased for both groups between the first and second trimester but the degree of decrease was more pronounced for people with obesity.

Correlation analysis was done per trimester and showed that BMI and fat mass were more closely related to hemodynamic measures during the first trimester. In the first trimester BMI positively correlated with SV $(r=0.54, p=0.04)$, TPRI $(r=0.56, p=0.04)$, and CO $(r=0.53, p=0.04)$. Fat mass showed a strong correlation with TPRI during the first trimester $(r=0.68, p=0.01)$.

BMI positively correlated with $\mathrm{CO}$ during the second trimester $(r=0.53, p=0.04)$ as did fat mass $(r=0.55$, $p=0.03$ ). During the third trimester, BMI, as well as fat mass, negatively correlated with TPR $(r=-0.56, p=0.05$; $r=-0.59, p=0.04$, respectively).

Further correlation analysis showed that the change in fat mass over the course of pregnancy significantly correlated with changes in TPR $(r=0.63, p=0.04)$, TPRI $(r=0.64$, 
Table 3 Anthropometric and hemodynamic data of pregnant people with and without obesity in the second (21-23 weeks) and third trimesters (34-36 weeks)

\begin{tabular}{|l|l|l|l|l|l|l|}
\hline & \multicolumn{4}{|l}{ Trimester 2 (21-23 weeks) } & \multicolumn{4}{l|}{ Trimester 3 (34-36 weeks) } \\
\cline { 2 - 7 } & Obese & Nonobese & $\boldsymbol{p}$ & Obese & Nonobese & $\boldsymbol{p}$ \\
\hline$n$ & 7 & 8 & NA & 6 & 7 & NA \\
\hline BMI $\left(\mathrm{kg} / \mathrm{m}^{2}\right)$ & 41.9 & 25.9 & $<0.01$ & 43.6 & 27.2 & $<0.01$ \\
\hline Fat mass (\%) & 40 & 26.3 & $<0.01$ & 38.9 & 29.9 & 0.01 \\
\hline SBP $(\mathrm{mm} \mathrm{Hg})$ & $118 \pm 15$ & $105 \pm 11$ & 0.09 & $116 \pm 16$ & $103 \pm 12$ & 0.10 \\
\hline DBP $(\mathrm{mm} \mathrm{Hg})$ & $70 \pm 13$ & $61 \pm 8$ & 0.10 & $73 \pm 11$ & $66 \pm 11$ & 0.32 \\
\hline MAP $(\mathrm{mm} \mathrm{Hg})$ & $80 \pm 7$ & $74 \pm 10$ & 0.25 & $87 \pm 12$ & $78 \pm 11$ & 0.19 \\
\hline SV $(\mathrm{mL})$ & $99 \pm 22$ & $73 \pm 11$ & 0.01 & $96 \pm 21$ & $73 \pm 15$ & 0.04 \\
\hline TPR $\left(\mathrm{dyn} / \mathrm{s} / \mathrm{cm}^{3}\right)$ & $756 \pm 151$ & $942 \pm 69$ & 0.01 & $842 \pm 188$ & $1,043 \pm 168$ & 0.07 \\
\hline TPRI & $1,634 \pm 312$ & $1,568 \pm 222$ & 0.65 & $1,826 \pm 367$ & $1,732 \pm 266$ & 0.6 \\
\hline CO $(\mathrm{L} / \mathrm{min})$ & $8.16 \pm 1.56$ & $6.46 \pm 0.82$ & 0.02 & $8.55 \pm 1.50$ & $6.23 \pm 1.43$ & 0.02 \\
\hline CI (L/min $\left./ \mathrm{m}^{2}\right)$ & $4.49 \pm 1.65$ & $3.88 \pm 0.40$ & 0.44 & $3.98 \pm 0.71$ & $3.7 \pm 0.66$ & 0.47 \\
\hline
\end{tabular}

Abbreviations: Cl, cardiac index; CO, cardiac output; DBP, diastolic blood pressure; MAP, mean arterial pressure; NA, indicates not applicable; SBP, systolic blood pressure; SV, stroke volume; TPR, total peripheral resistance; TPRI, total peripheral resistance index.

Note: Data are expressed as mean \pm standard deviation.

$p=0.03), \quad \mathrm{CO}(r=-0.71, p=0.01), \quad$ and $\operatorname{CO}(r=-0.68$, $p=0.02$; - Figs. 1,2,3,4).

\section{Discussion}

The aim of this study was to profile hemodynamic parameters longitudinally throughout pregnancy in people with obesity and normal weight using NICOM and to record pregnancy outcomes.

In this small pilot study, we identified important cardiovascular differences in pregnant people with and without obesity throughout gestation. Given the small numbers, we were not able to correlate these hemodynamic changes to maternal and fetal outcomes.

Classically, obesity has been associated with a higher cardiovascular workload. To offset this, several hemodynam-



Fig. 1 Correlation between fat mass change and total peripheral resistance (TPR) change during pregnancy. ic changes take place. For example, the Frank-Starling curve shows a leftward shift, with afterload reduction which is mainly due to decreased TPR. In some populations, the higher levels of the adipocytokine leptin which is released by fat cells have been associated with this drop in TPR. ${ }^{29}$

With higher levels of adiposity, individuals with obesity have higher circulating blood volume, as well as a higher $\mathrm{SV}^{30}$ There is also a tendency toward higher resting heart rate. As CO is the product of SV and heart rate, individuals with obesity typically have a higher CO than age- and sexmatched normal weight individuals. Over time, this compensatory mechanism can affect the myocardium causing left and right ventricular enlargement and hypertrophy. Unchecked, chamber dilation can progress to diastolic and systolic ventricular dysfunction which in severe cases can lead to overt heart failure.

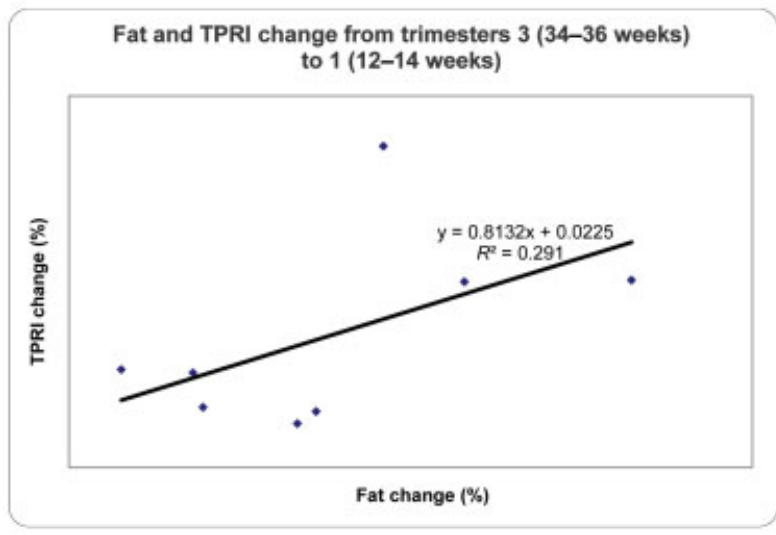

Fig. 2 Correlation between fat mass change and total peripheral resistance index (TPRI) change during pregnancy. 
Fat and $\mathrm{CO}$ change from trimesters 3 (34-36 weeks) to 1 (12-14 weeks)

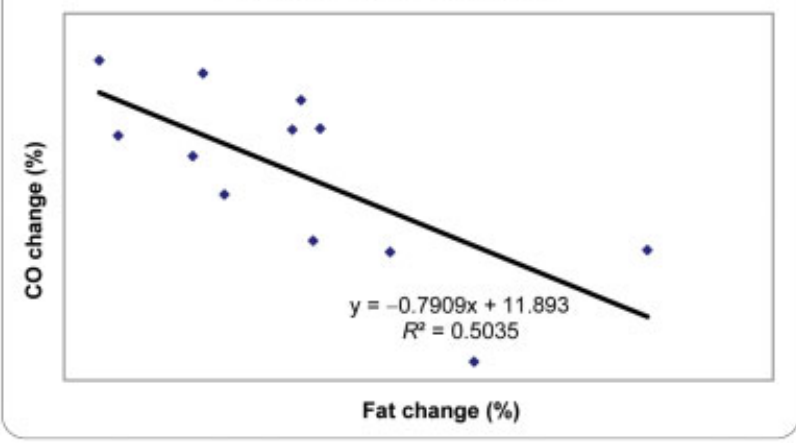

Fig. 3 Correlation between fat mass change and cardiac output (CO) change during pregnancy.

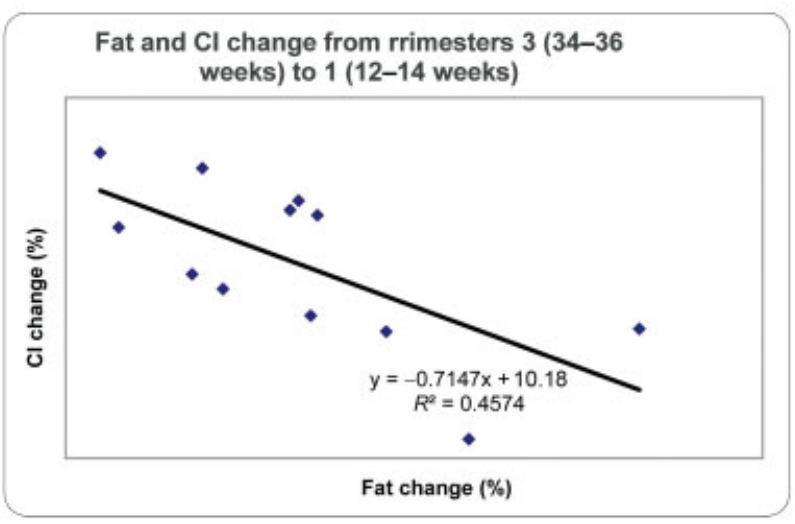

Fig. 4 Correlation between fat mass change and cardiac index $(\mathrm{Cl})$ change during pregnancy.

It is important to note that in normal pregnancies, some of the hemodynamic changes seen with obesity are also present. For example, there is a 40 to $50 \%$ increase in circulating blood volume. SV and CO also increase while TPR falls. ${ }^{30}$

SV fell consistently throughout pregnancy in our study patients. SV is physiologically the difference between enddiastolic volume (EDV) and end-systolic volume (ESV); $(S V=E D V-E S V) .{ }^{31}$ None of study patients showed clinical signs of heart failure, suggesting that ventricular systolic function remained adequate. We speculate that the decrease in SV may be related to mild ventricular diastolic impairment.

In our study, we observed an association between changes in fat mass and hemodynamic indices. With fat mass gain, there is a trend toward higher TPR and lower CO. These changes may be related to adipocytokines (e.g., leptin, ghrelin, and adiponectin) which are secreted from adipose tissue and are present in higher concentration in individuals with obesity. Adipocytokines, such as leptin, are also higher in pregnancy in people with and without obesity ${ }^{32}$ due to secretion by the placenta. Leptin levels rise during pregnancy and peak during the second trimester. Elevated leptin levels have been seen with gestational diabetes ${ }^{33}$ and gestational hypertension/preeclampsia. ${ }^{34}$ Leptin levels were not measured in this study, so it is unknown what role they may have played in maternal hemodynamic alterations.
It is also noteworthy that most of the hemodynamic and anthropometric changes noted in the study group occurred between the first and second trimesters. An epidemiological study by Villamor and Cnattingius ${ }^{35}$ suggested that weight gain between pregnancies was associated with higher incidence of adverse fetal outcome. Intrapregnancy weight gain has also been associated with adverse maternal and fetal outcome. ${ }^{36,37}$

Although our numbers are too small to draw specific conclusions, we speculate that fat mass gain between the first and second trimesters, in addition to the hemodynamic changes already present due to obesity and pregnancy, may have caused some degree of left ventricular diastolic dysfunction and therefore, lower SVs.

This hypothesis could not be confirmed due to lack of echocardiographic studies on both cohorts. The hypothetical causality between obesity gain and altered NICOM parameters, and the potential for left ventricular diastolic dysfunction, can be better explored in future studies. Our study suggests that incorporating echocardiographic parameters with NICOM in pregnant populations with obesity may clarify this matter.

We identified that our patients with obesity maintained stable $\mathrm{CO}$ and $\mathrm{CI}$. This fact might be reflective of young age and the ability to compensate with higher heart rates. Extrapolating from this, for people with obesity at the start of pregnancy, more focused fat mass management between the first and second trimesters could confer better hemodynamic function, mitigating the higher TPR, and lower $\mathrm{CO} / \mathrm{CI}$.

This pilot study was designed to assess the clinical utility of NICOM in pregnant people with and without obesity. It was possible to identify that NICOM was useful in tracking cardiovascular and hemodynamic changes throughout the course of gestation. Further studies, including echocardiographic assessments, are necessary to corroborate these findings. It would be interesting to observe whether the hemodynamic changes identified in this pilot study are resolved in the postpartum period and how such resolution might be explained by changes in weight, BMI, and/or fat mass.

\section{Limitations}

Future work with larger patient groups could investigate the possible causative role of the adipocytokines (leptin and adiponectin) in the cardiovascular changes seen in pregnancy affected by obesity. It is well known that leptin can cause chronic oxidative stress in endothelial cells, stimulate migration and proliferation of vascular smooth cells, and induce calcification of vascular cells, thus contributing to vascular pathology. ${ }^{38-40}$ In patients with obesity and diabetes, the elevation of leptin levels also causes a reduction of nitric oxide (NO) and attenuation of NO vasodilation, contributing to increased vascular resistance. ${ }^{41,42}$

\section{Conclusion}

Obesity remains one of the major health care concerns of our time and obesity in pregnancy has serious adverse implications for our patients and maternal cardiac health. Although 
our numbers are too small in this pilot study to draw inference, we suggest that further investigation into the role of weight gain and fat mass management between the first and second trimesters is warranted, as this period coincides with potentially detrimental cardiovascular changes.

\section{Financial Support}

There was no financial support to this research.

\section{Conflicts of Interest \\ None declared.}

\section{Acknowledgments}

Authors thank Dr. Junmin Yang for sterling assistance with the statistical analysis included in this paper.

\section{References}

1 WHO. Obesity and overweight. Accessed December 21, 2021 at: http://www.who.int/mediacentre/factsheets/fs311/en/

2 Danias PG, Tritos NA, Stuber M, Kissinger KV, Salton CJ, Manning WJ. Cardiac structure and function in the obese: a cardiovascular magnetic resonance imaging study. J Cardiovasc Magn Reson 2003;5(03):431-438

3 de Simone G, Devereux RB, Daniels SR, et al. Stroke volume and cardiac output in normotensive children and adults. Assessment of relations with body size and impact of overweight. Circulation 1997;95(07):1837-1843

4 Poirier P, Giles TD, Bray GA, et al; American Heart Association; Obesity Committee of the Council on Nutrition, Physical Activity, and Metabolism. Obesity and cardiovascular disease: pathophysiology, evaluation, and effect of weight loss: an update of the 1997 American Heart Association Scientific Statement on Obesity and Heart Disease from the Obesity Committee of the Council on Nutrition, Physical Activity, and Metabolism. Circulation 2006; 113(06):898-918

5 Robinson MR, Scheuermann-Freestone M, Leeson P, et al. Uncomplicated obesity is associated with abnormal aortic function assessed by cardiovascular magnetic resonance. J Cardiovasc Magn Reson 2008;10:10

6 Rider OJ, Petersen SE, Francis JM, et al. Ventricular hypertrophy and cavity dilatation in relation to body mass index in women with uncomplicated obesity. Heart 2011;97(03):203-208

7 Kenchaiah S, Evans JC, Levy D, et al. Obesity and the risk of heart failure. N Engl J Med 2002;347(05):305-313

8 He J, Ogden LG, Bazzano LA, Vupputuri S, Loria C, Whelton PK. Risk factors for congestive heart failure in US men and women: NHANES I epidemiologic follow-up study. Arch Intern Med 2001;161(07):996-1002

9 Heslehurst N, Simpson H, Ells LJ, et al. The impact of maternal BMI status on pregnancy outcomes with immediate short-term obstetric resource implications: a meta-analysis. Obes Rev 2008;9 (06):635-683

10 American College of Obstetricians and Gynecologists. ACOG Committee opinion no. 549: obesity in pregnancy. Obstet Gynecol 2013;121(01):213-217

11 Schrauwers C, Dekker G. Maternal and perinatal outcome in obese pregnant patients. J Matern Fetal Neonatal Med 2009;22(03):218-226

12 O'Brien TE, Ray JG, Chan WS. Maternal body mass index and the risk of preeclampsia: a systematic overview. Epidemiology 2003; 14(03):368-374

13 Sebire NJ, Jolly M, Harris JP, et al. Maternal obesity and pregnancy outcome: a study of 287,213 pregnancies in London. Int J Obes Relat Metab Disord 2001;25(08):1175-1182
14 Chatterjee K. The Swan-Ganz catheters: past, present, and future. A viewpoint. Circulation 2009;119(01):147-152

15 Chung JH, Melsop KA, Gilbert WM, et al. Increasing pre-pregnancy body mass index is predictive of a progressive escalation in adverse pregnancy outcomes. J Matern Fetal Neonatal Med 2012;25(09):1635-1639

16 Weiss JL, Malone FD, Emig D, et al; FASTER Research Consortium. Obesity, obstetric complications and cesarean delivery rate-a population-based screening study. Am J Obstet Gynecol 2004; 190(04):1091-1097

17 Kristensen J, Vestergaard M, Wisborg K, Kesmodel U, Secher NJ. Pre-pregnancy weight and the risk of stillbirth and neonatal death. BJOG 2005;112(04):403-408

18 Jolly MC, Sebire NJ, Harris JP, Regan L, Robinson S. Risk factors for macrosomia and its clinical consequences: a study of 350,311 pregnancies. Eur J Obstet Gynecol Reprod Biol 2003;111(01):9-14

19 Stothard KJ, Tennant PW, Bell R, Rankin J. Maternal overweight and obesity and the risk of congenital anomalies: a systematic review and meta-analysis. JAMA 2009;301(06):636-650

20 Cedergren MI. Maternal morbid obesity and the risk of adverse pregnancy outcome. Obstet Gynecol 2004;103(02):219-224

21 Reynolds RM, Allan KM, Raja EA, et al. Maternal obesity during pregnancy and premature mortality from cardiovascular event in adult offspring: follow-up of 1323275 person years. BMJ 2013;347:f4539

22 Keren H, Burkhoff D, Squara P. Evaluation of a noninvasive continuous cardiac output monitoring system based on thoracic bioreactance. Am J Physiol Heart Circ Physiol 2007;293(01): H583-H589

23 Squara P, Rotcajg D, Denjean D, Estagnasie P, Brusset A. Comparison of monitoring performance of Bioreactance vs. pulse contour during lung recruitment maneuvers. Crit Care 2009;13(04):R125

24 Raval NY, Squara P, Cleman M, Yalamanchili K, Winklmaier M, Burkhoff D. Multicenter evaluation of noninvasive cardiac output measurement by bioreactance technique. J Clin Monit Comput 2008;22(02):113-119

25 Monteith C, McSweeney L, Breatnach CR, et al. Non-invasive cardiac output monitoring (NICOM) can predict the evolution of uteroplacental disease-Results of the prospective HANDLE study. Eur J Obstet Gynecol Reprod Biol 2017;216:116-124

26 Doherty A, El-Khuffash A, Monteith C, et al. Comparison of bioreactance and echocardiographic non-invasive cardiac output monitoring and myocardial function assessment in primagravida women. Br J Anaesth 2017;118(04):527-532

27 Doherty A, Ohashi Y, Downey K, Carvalho JC. Non-invasive monitoring based on bioreactance reveals significant hemodynamic instability during elective cesarean delivery under spinal anesthesia [in multiple languages]. Rev Bras Anestesiol 2011;61 (03):320-325

28 Ohashi Y, Ibrahim H, Furtado L, Kingdom J, Carvalho JC. Noninvasive hemodynamic assessment of non-pregnant, healthy pregnant and preeclamptic women using bioreactance [corrected]. Rev Bras Anestesiol 2010;60(06):603-613, 335-340. Doi: 10.1016/S0034-7094(10)70075-1

29 Schutte R, Huisman HW, Schutte AE, Malan NT. Leptin is favourably associated with vascular function in obese Caucasians, but not in obese Africans. J Hum Hypertens 2005;19(12):933-939

30 Marchi J, Berg M, Dencker A, Olander EK, Begley C. Risks associated with obesity in pregnancy, for the mother and baby: a systematic review of reviews. Obes Rev 2015;16(08):621-638

31 McMurray JJV, Adamopoulos S, Anker SD, et al; ESC Committee for Practice Guidelines. ESC Guidelines for the diagnosis and treatment of acute and chronic heart failure 2012: The Task Force for the Diagnosis and Treatment of Acute and Chronic Heart Failure 2012 of the European Society of Cardiology. Developed in collaboration with the Heart Failure Association (HFA) of the ESC. Eur Heart J 2012;33(14):1787-1847

32 Highman TJ, Friedman JE, Huston LP, Wong WW, Catalano PM. Longitudinal changes in maternal serum leptin concentrations, 
body composition, and resting metabolic rate in pregnancy. Am J Obstet Gynecol 1998;178(05):1010-1015

33 Lea RG, Howe D, Hannah LT, Bonneau O, Hunter L, Hoggard N. Placental leptin in normal, diabetic and fetal growth-retarded pregnancies. Mol Hum Reprod 2000;6(08):763-769

34 Mise H, Sagawa N, Matsumoto T, et al. Augmented placental production of leptin in preeclampsia: possible involvement of placental hypoxia. J Clin Endocrinol Metab 1998;83(09): 3225-3229

35 Villamor E, Cnattingius S. Interpregnancy weight change and risk of adverse pregnancy outcomes: a population-based study. Lancet 2006;368(9542):1164-1170

36 Mochhoury L, Razine R, Kasouati J, Kabiri M, Barkat A. Body mass index, gestational weight gain, and obstetric complications in Moroccan population. J Pregnancy 2013;2013:379461

37 Johnson J, Clifton RG, Roberts JM, et al; Eunice Kennedy Shriver National Institute of Child Health and Human Development
(NICHD) Maternal-Fetal Medicine Units (MFMU) Network* Pregnancy outcomes with weight gain above or below the 2009 Institute of Medicine guidelines. Obstet Gynecol 2013;121(05): 969-975

38 Bouloumie A, Marumo T, Lafontan M, Busse R. Leptin induces oxidative stress in human endothelial cells. FASEB J 1999;13(10): 1231-1238

39 Oda A, Taniguchi T, Yokoyama M. Leptin stimulates rat aortic smooth muscle cell proliferation and migration. Kobe J Med Sci 2001;47(03):141-150

40 Parhami F, Tintut Y, Ballard A, Fogelman AM, Demer LL. Leptin enhances the calcification of vascular cells: artery wall as a target of leptin. Circ Res 2001;88(09):954-960

41 Sweeney G. Cardiovascular effects of leptin. Nat Rev Cardiol 2010; 7(01):22-29

42 Poetsch MS, Strano A, Guan K. Role of leptin in cardiovascular diseases. Front Endocrinol (Lausanne) 2020;11:354 